\title{
EL DERECHO A LA IDENTIDAD BIOLÓGICA DE LAS PERSONAS NACIDAS MEDIANTE REPRODUCCION ASISTIDA EN LA DOCTRINA, JURISPRUDENCIA Y LEGISLACION PERUANA
}

\author{
THE RIGHT OF IDENTITY OF THE BIOLOGICAL PEOPLE BORN BY \\ ASSISTED REPRODUCTION IN DOCTRINE, JURISPRUDENCE AND \\ PERUVIAN LEGISLATION
}

Ronald Cárdenas Krenz ${ }^{1}$

\section{Resumen}

El artículo aborda el tema del derecho de las personas nacidas mediante reproducción asistida con intervención de un tercero, a conocer su origen biológico, desde la perspectiva de la legislación, la doctrina y la jurisprudencia en el Perú.

\section{Palabras clave}

Identidad biológica. Derecho a la identidad. Reproducción asistida.

\begin{abstract}
The article discusses the issue of the right of people born through assisted reproduction, with the intervention of a third party, to know its biological origin from the perspective of the law, doctrine and jurisprudence in Peru.
\end{abstract}

\section{Key Words}

Biological identity. Right to identity. Assisted reproduction.

\footnotetext{
Magister en Bioética y Biojurídica. Magister en Derecho Civil y Comercial. Past Decano y profesor de la Facultad de Derecho de la Universidad Femenina del Sagrado Corazón. Miembro del Instituto de Investigación Científica y Profesor de la Facultad de Derecho de la Universidad de Lima. Miembro Correspondiente de la Academia de Derecho y Ciencias Sociales de Córdoba (Argentina), Profesor en la Universidad ESAN, en la Maestría de la Universidad San Martín de Porres y en la Maestría de la USAT. Ha sido miembro del Comité de Ética de la Facultad de Biología de la Universidad Nacional Mayor de San Marcos.
} 


\section{INTRODUCCIÓN}

En los procedimientos de fecundación asistida con intervención de un tercero, suele ser un principio fundamental el anonimato del dador. Frente a ello, postulamos que toda persona tiene derecho a conocer su origen biológico, al amparo del derecho a la salud, el derecho a la identidad, el derecho a saber, el principio de no discriminación, el derecho a la verdad, el principio del interés superior del niño, el derecho al acceso a los datos personales, el derecho a la información y el derecho a la dignidad.

Sobre el tema, hemos tratado ya en un artículo anterior publicado en el año $2013^{2}$, y, más ampliamente, en la tesis de maestría en bioética y biojurídica que sustentáramos en el año 2014 ${ }^{3}$. En tal virtud, las siguientes páginas tienen por objeto tratar el tema a partir de la jurisprudencia, la legislación y la doctrina nacional.

Desde sus orígenes, la difusión de las técnicas de reproducción asistida ha ido acompañada de la invocación del anonimato y la intimidad como supuestos derechos del dador y de los padres, frente al deseo del hijo de conocer quién es su padre biológico. Sin embargo, ello cada vez va siendo más cuestionado en diversos países, habiendo algunos casos emblemáticos vinculados con el tema como los de Bertold Wiesner en Inglaterra, Henrik Koch en Dinamarca, Olivia Platten en Canadá, "Sarah P." en Alemania, Katrina Clark, en Estados Unidos, y, en América Latina, dos sentencias dadas en mayo de 2014, tanto en México como en Argentina, reconociendo expresamente este derecho. Ello sin contar con que, poco a poco, diversas legislaciones -como el caso de Inglaterra, Holanda y Suecia- también lo vienen haciendo.

\section{JURISPRUDENCIA NACIONAL Y DERECHO A LA IDENTIDAD}

En el Perú, no existe una norma expresa que consagre el derecho de las personas a conocer su identidad biológica, por lo que debemos aproximarnos al tema desde una perspectiva jurisprudencial y doctrinaria. En cuanto a la jurisprudencia, puede decirse que, en los últimos años, han empezado a aparecer algunos fallos; unos con ideas muy plausibles y otros

Cárdenas Krenz, Ronald (2013) La información sobre el origen biológico como derecho fundamental de la persona. En: Lumen No. 9, revista de la Facultad de Derecho de la Universidad Femenina del Sagrado Corazón. Lima. El trabajo fue presentado en el Congreso de la Federación Internacional y del Caribe de Instituciones de Bioética, realizado en Guanajuato (México) en abril del 2013.

Cárdenas Krenz, Ronald (2014) El derecho de las personas concebidas mediante técnicas de reproducción asistida a conocer su identidad biológica, desde una perspectiva jurídica. Tesis para optar el grado de Magister en Bioética y Biojurídica por la Universidad Santo Toribio de Mogrovejo. 
más bien discutibles, poniendo en evidencia la ausencia de una formación en bioética; si bien no es culpa de los jueces el que durante sus años de formación universitaria la Bioética no formara parte de su currículo de estudios, igual es un imperativo la actualización en el conocimiento, más todavía en un área académica tan importante que aborda cuestiones de tan alta relevancia.

Toda persona tiene derecho a su identidad, tal como reza el inciso 1 del artículo 2 de la Constitución, pudiendo definirse la identidad personal, siguiendo a Fernández Sessarego, como "todo aquello que hace que cada cual sea "uno mismo" y "no otro".

Por otro lado, el artículo 396 del Código Civil peruano dispone que: "El hijo de mujer casada no puede ser reconocido sino después de que el marido impugne la paternidad y obtenga sentencia favorable", lo que implica entonces que la ley privilegia la presunción de paternidad matrimonial a pesar de que la realidad diga que existe más bien una paternidad extramatrimonial. Ello es una consecuencia lógica de lo prescrito por el mismo Código de 1984, para el cual todo hijo habido durante el matrimonio se presume que es del marido (artículo 361) y solo éste puede cuestionar la paternidad (artículo 363), presumiéndose que es matrimonial aun cuando la esposa declare que no es de él o incurra en adulterio (artículo 362); existiendo, además, un estrecho tiempo de 90 días para contestar la paternidad (artículo 364).

Sin embargo, en algunos fallos se viene advirtiendo que dicha normativa colisionaría en parte con lo dispuesto en el inciso 1 del artículo 2 de la Constitución de 1993, el cual reconoce que toda persona tiene derecho a la identidad.

Bajo dicho amparo, en un caso en el que una persona pretendía se le reconozca la paternidad del hijo de una mujer casada, la Sala Civil Transitoria de la Corte Suprema inaplicó los artículos 396 y 404 del Código Civil (Casación No. 2726-2012-Del Santa), estimando que, por encima de dicha regulación, prima la identidad biológica del menor, teniendo en cuenta el interés superior del niño, como también el estado constante de familia de la menor materia del proceso con sus padres biológicos, toda vez que éstos venían desarrollando con ella una vida familiar, lo cual no fue desvirtuado. ${ }^{5}$

Fernández Sessarego, Carlos (1992) Derecho a la identidad personal. Buenos Aires: Astrea, p. 113.

La demanda había sido declarada fundada en primera instancia y declarada improcedente en la segunda (argumentándose que el padre biológico carecía de interés para obrar respecto a un proceso sobre impugnación de reconocimiento de paternidad). Recuperado de: http:/ / laley.pe/not/1422/padre-biológico- puede-reconocer-ahijo-de-mujer-casada Consultada el 30 de abril de 2014. 
Es interesante mencionar, adicionalmente, el control difuso realizado por la Sala de Familia de Lima, aprobado por la Sala de Derecho Constitucional y Social de la Corte Suprema, a través del cual -señala Huamancayo ${ }^{6}$, en diversos expedientes civiles sobre acción de contestación de la paternidad y acción de reconocimiento del hijo extramatrimonial, se han inaplicado los artículos 364 y 400 del Código Civil ${ }^{7}$, por considerar que el plazo que consideran atenta contra el Derecho a la Identidad. Dichas sentencias -refiere el mismo autor- son las recaídas en los expedientes No. 183515-2003-00233-0 y 860-2002 de la Sala Especializada de Familia y el expediente No. 20030839-251801-JF-01 del Primer Juzgado de Familia de Chimbote.

Otro caso en el que la Corte Suprema también se ha pronunciado por la inaplicación del artículo 400 del Código Civil privilegiando el derecho a la identidad, considerando que no existe razón objetiva y razonable que justifique fijar en 90 días el plazo para negar el reconocimiento indebido por uno de los padres, se dio con motivo de la elevación en consulta del Expediente No. 229-2010-Puno. Al respecto, estimó la Corte que el derecho a la identidad no debe limitarse en su protección por plazos legalmente establecidos, considerando su trascendencia como derecho fundamental en el desarrollo de la persona; así, deja establecido que el mencionado art. 400 no puede ser un obstáculo para que el Estado preserve el derecho a la identidad (Consulta Exped. No. 293-2001-Lima). ${ }^{8}$

También es interesante lo resuelto por la Sala Constitucional y Social Permanente de la Corte Suprema de Justicia en julio del 2010, con motivo de una consulta respecto al expediente No. 1388-2010 (Arequipa, sentencia del 08.07.2010) respecto a la constitucionalidad de los artículos $402{ }^{9}$ inciso

Huamancayo Pierrend, Juan Carlos (2009) El Derecho a la Identidad vs. el Derecho a la Verdad Biológica. ¿Se está aplicando correctamente el control difuso en el caso de los artículos 364 y 400 del Código Civil?. En: Persona, Derecho y Libertad. Nuevas Perspectivas. Escritos en Homenaje al Profesor Carlos Fernández Sessarego. Calderón Puertas, Carlos; Elisa Zapata J. y Carlos Agurto G. (Coordinadores). Lima: Editora Jurídica Motivensa, p. 135.

El artículo 364 del Código Civil, refiriéndose a la acción para negar al hijo ajeno nacido en el matrimonio, señala lo siguiente: La acción contestatoria debe ser interpuesta por el marido dentro del plazo de noventa días contados desde el día siguiente del parto, si estuvo presente en el lugar, o desde el día siguiente de su regreso, si estuvo ausente.

A su vez, el artículo 400, al referirse al hijo extramatrimonial, señala que el plazo para negar el reconocimiento es de noventa días, a partir de aquel en que se tuvo conocimiento del acto.

La Ley, año 6, No. 65. Lima: edición del 1 al 30 de junio de 2013, p. 8.

Procedencia de la declaración judicial de paternidad extramatrimonial

"Artículo 402.- La paternidad extramatrimonial puede ser judicialmente declarada:

1. Cuando exista escrito indubitado del padre que la admita.

2. Cuando el hijo se halle, o se hubiese hallado hasta un año antes de la demanda, en la posesión constante del estado de hijo extramatrimonial, comprobado por actos directos del padre o de su familia.

3. Cuando el presunto padre hubiera vivido en concubinato con la madre en la época de la concepción. Para este efecto se considera que hay concubinato cuando un varón y una mujer, sin estar casados entre sí, hacen vida de tales. 
6 y $404^{10}$ del Código Civil. Sobre el particular, la Sala se pronunció en el sentido que la exigencia de requerir sentencia previa de impugnación de la paternidad e ignorar el resultado de un examen de ADN si involucra al hijo de una mujer casada, son normas contrarias a la Constitución por afectar el derecho a la identidad del niño y negar la identidad biológica. ${ }^{11}$

Asimismo, existen interesantes pronunciamientos del Tribunal Constitucional que reconocen el derecho de toda persona a investigar su propia filiación; si bien estos fallos han sido dados en el marco de casos vinculados con el tema del Derecho de Familia, sus consideraciones son perfectamente extensivas al conocimiento de la verdad biológica como derecho individual. ${ }^{12}$

El Tribunal Constitucional ha señalado que el derecho a la identidad del menor prevalece incluso sobre la cosa juzgada en los procesos de filiación. ${ }^{13}$ Y es que, como dice Faiella, resulta evidente que el derecho por antonomasia a tener en cuenta cuando se plantea la posibilidad de revisar la cosa juzgada en materia de filiación es el derecho a la identidad. ${ }^{14}$

Finalmente, en este repertorio de casos, vale mencionar uno sobre reproducción asistida, resuelto mediante sentencia Cas. No. 5003-2007 de fecha 06.05.2008, en el que la Sala Civil de la Corte Suprema resolvió la casación interpuesta por M.C.O.C. en representación de su menor hijo O.F.Q.O., en la demanda que presentara contra el reconocimiento

4. En los casos de violación, rapto o retención violenta de la mujer, cuando la época del delito coincida con la de la concepción.

5. En caso de seducción cumplida con promesa de matrimonio en época contemporánea con la concepción, siempre que la promesa conste de manera indubitable.

6. Cuando se acredite el vínculo parental entre el presunto padre y el hijo a través de la prueba del ADN u otras pruebas genéticas o científicas con igual o mayor grado de certeza.

Lo dispuesto en el presente inciso no es aplicable respecto del hijo de la mujer casada cuyo marido no hubiese negado la paternidad.

El juez desestimará las presunciones de los incisos precedentes cuando se hubiera realizado una prueba genética u otra de validez científica con igual o mayor grado de certeza."

10 Declaración judicial de paternidad del hijo de mujer casada:"Artículo 404.- Si la madre estaba casada en la época de la concepción, sólo puede admitirse la acción en caso que el marido hubiera contestado su paternidad y obtenido sentencia favorable".

11 Siverino, Paola. (2013) Cuestionamiento de la filiación matrimonial por la esposa. En: Revista Diálogo con la Jurisprudencia No. 179. Lima: Gaceta Jurídica, edición de agosto 2013, p. 14. El caso trata de una persona que declara ser el padre del niño de una mujer casada, sin que sea desmentido por el esposo pero sin que este tampoco haya impugnado la paternidad; una prueba de ADN confirma la verdad biológica de la paternidad, solicitando el accionante se inscriba al hijo como suyo.

12 Para más detalle, véase: Arias Stella, Fernando (2012) Derechos Humanos y las sentencias del Tribunal Constitucional que consagran el derecho a investigar la propia filiación. Lima: Instituto de Patología y Biología Molecular "Arias Stella".

13 La STC Exp. No. 0550-2008-PA/TC permitió que se vuelva a demandar una paternidad extramatrimonial por filiación cuando en un proceso anterior entre las mismas partes, sobre el mismo tema, se había declarado infundada la demanda, basándose en el hecho que en el primer proceso no había habido la posibilidad de recurrir a la prueba de ADN (Revista Actualidad Jurídica. Tomo 211. Lima: Gaceta Jurídica, edición de junio 2011, p. 74).

14 Faiella, Rocío Liliana (2009) El ADN pone en jaque la inmutabilidad de la cosa juzgada. En: Revista Jurídica Aequitas. Facultad de Ciencias Jurídicas de la Universidad del Salvador. 3ª Etapa. Año III. Número III, p. 45. 
de maternidad efectuado por M.A.A.D. respecto de la menor A.B.A.D., impugnación que fue formulada alegando que la demandada no era la madre biológica de la menor, pues fue inseminada artificialmente con el óvulo de una mujer distinta, usando el esperma del esposo de la recurrente, C.O.Q.C., sin el consentimiento de éste, mediante la técnica de la "ovodonación" que no está permitida en nuestro país, conforme se colige del art. 7 de la Ley General de Salud.

Como de esta manera O.F.Q.O. resultó siendo hermano paterno de la menor, que la demandada ha reconocido como su hija -conforme a la prueba de ADN de donde se colige que el padre de los dos menores es C.O.Q.C.-, el reconocimiento fue cuestionado por no concordar con la realidad biológica.

En primera instancia, la demanda había sido declarada infundada por considerarse que la accionante no había acreditado que con el reconocimiento se haya afectado directa o indirectamente al hijo de la demandante, careciendo por ende de interés para obrar. Sin embargo, la Corte Suprema, finalmente, resolvió fundada la casación, ordenando que el Juez de la causa expida nueva resolución, autorizando entonces el cuestionamiento de la paternidad por un medio hermano como tercero legitimado en caso de una reproducción asistida, pero evitando pronunciarse sobre las cuestiones de fondo subyacentes al caso. ${ }^{15}$ Lo interesante, en todo caso aquí, es que se impugna la maternidad sobre la base que el reconocimiento efectuado no coincide con la realidad biológica.

\section{DERECHO A LA IDENTIDAD BIOLÓGICA, REPRODUCCIÓN ASISTIDA Y LEGISLACIÓN NACIONAL}

Siendo que la discusión sobre el derecho de la persona a conocer su origen biológico se vincula directamente con la aplicación de las técnicas de reproducción asistida, desde el punto de vista del Derecho Civil, y teniendo en cuenta que no existe una ley específica sobre la materia, debe tenerse presente entonces diversas normas de nuestro ordenamiento jurídico.

\footnotetext{
15 “La Corte Suprema (...) pierde la oportunidad de hacer un análisis sobre maternidad y la filiación derivadas de una Teras y se pierde en disquisiciones de índole procesal de la legitimidad para obra y del legítimo interés, marginando el tema sustancial vinculado al motivo de la demanda de impugnación de reconocimiento de maternidad presentado" (Cieza, Jairo, 2011. "La técnica de reproducción humana asistida y la Corte Suprema: ¿Quién entonces es la madre?". Recuperado de: http:/ /legisprudencia.pe/blogs/2011/04/26/la-técnica-de-reproducción-humanaasistida-y-la.corte-suprema-\%C2\%BFquien-entonces-es-la-madre/ Consultado el 20 de julio de 2015.
} 
El art. V del Título Preliminar del Código Civil señala que "es nulo el acto jurídico contrario a las leyes que interesan al orden público o a las buenas costumbres"16. Siendo claro que la autonomía de la voluntad, bajo cuyo amparo se acuerda el anonimato en los contratos de reproducción asistida, no puede ir contra el orden público, es necesario precisar este concepto: Se trata del conjunto de normas jurídicas y principios constitutivos del orden social y que por ello son de ineludible cumplimiento para todos los ciudadanos. De acuerdo con Messineo, podemos hablar de actos contrarios al "orden público" cuando se atenta contra "los principios fundamentales y los intereses generales -deducibles de las normas coactivas de la ley (aunque no estén formulados en normas concretas)sobre los cuales descansa el ordenamiento jurídico del Estado (...) y que, por tanto, ellos mismos son imperativos e inderogables". ${ }^{17}$

Ejemplos de contratos que atenten contra el orden público que se mencionan típicamente, pueden ser el de una persona que autorice que le quiten los ojos en vida para ser trasplantados a otra persona; el trasplante de cara de una persona viva a otra; la compraventa de un cadáver; la venta o subasta de órganos; el compromiso suscrito por una persona de no salir embarazada; y podríamos agregar también aquí el acuerdo de no revelar a una persona la verdad de su origen biológico.

Junto con el concepto de orden público, tenemos el de buenas costumbres, el cual tiene que ver con la moral social, compuesta por normas y principios que rigen en un lugar y en un momento determinado. Pueden mencionarse como ejemplos de actos contrarios a las buenas costumbres: Las peleas de perros, el contrato por el que una persona se obliga a tener relaciones sexuales con un grupo de individuos, la subasta de la virginidad o, en algunos países como el nuestro, la práctica del top less en las playas.

Caerían dentro de la idea de actos contra el orden público y las buenas costumbres: el uso del vientre de un animal para el desarrollo de un embrión humano (o viceversa), la subasta de embriones, o el contrato mediante el cual una persona celebra un acuerdo para tomar los servicios de fecundación

16 "El acuerdo de voluntades es la razón de ser del contrato. Sin embargo, la voluntad de los sujetos de derecho no es absoluta, irrestricta; la misma está limitada por el orden público y las buenas costumbres" (Morales Godo, Juan, 2006, ¿Somos libres, seámoslo siempre? (A propósito de la autonomía de la voluntad y el orden público). En: Varios Autores. Libro homenaje a Fernando Vidal Ramírez. Lima: Idemsa, p. 252).

17 Messineo, Francesco (1986) Doctrina General del Contrato. Tomo I. Buenos Aires: Ediciones Jurídicas Europa-América. p. 486. Por su parte, Morales Godo señala: “El orden público no es una noción universal, pues su contenido varía espacial y temporalmente en función a la idiosincracia cultural y a los sistemas políticos sociales imperantes en una comunidad, que van generando sistemas de valores, modos de comportamiento y principios éticos, los que deben ser cotejados en la interpretación de las normas" (Morales Godo, Juan, 2006, op. cit., p. 270). 
asistida de una clínica con la condición que el niño no nazca con ningún defecto físico o tenga determinado sexo.

Cabe tener en cuenta que el art. 1354 del Código Civil peruano permite a las partes determinar libremente el contenido del contrato, siempre que no se atente contra norma legal de carácter imperativo. El art. 1355, por otro lado, dispone que la ley puede imponer reglas o limitaciones a los contratos por razones de interés público, social o ético; y, adicionalmente, el art. 1356 prescribe que las disposiciones de la ley sobre contratos son supletorias de la voluntad de las partes, salvo que sean imperativas.

En cuanto a la Constitución del Estado, tenemos que el art. 2 hace referencia a que toda persona tiene derecho a la vida, a su identidad, a su integridad moral, psíquica y física y a su libre desarrollo y bienestar (inc. 1); a no ser discriminada (inc. 2); a la libertad de información (...) a la libertad de contratación siempre que sea con fines lícitos y no se contravengan las leyes de orden público (inc. 14), entre otras garantías.

También es importante mencionar que, aunque no existe una norma expresa que desarrolle en nuestro ordenamiento jurídico el Derecho a la Verdad, éste puede encontrar amparo en el artículo 3 de la Constitución del Estado. ${ }^{18}$

Es de recordar que la norma que trata con más detalle los temas de reproducción asistida es la Ley 26842, Ley General de Salud, del año 1997. Ella autoriza a recurrir a las técnicas de reproducción asistida para solucionar problemas de infertilidad, siempre que la madre biológica y la madre gestante sean la misma persona; asimismo, prohíbe expresamente la clonación (artículo 7).

Cabe agregar que, desde un punto de vista positivo, del artículo 7 de la Ley General de Salud, se desprende la prohibición del contrato de vientre de alquiler; ello aparte de las objeciones que desde la Constitución, el Código Civil, la jurisprudencia y la doctrina se pueden plantear a dicha figura, pudiendo observarse aquí un límite claro a la autonomía de la voluntad, en donde podría postularse incluso objeciones desde la perspectiva del orden público y las buenas costumbres.

18 Luego de la larga enumeración de derechos de la persona que hace el artículo 2 de la Carta Magna, el artículo 3 dispone lo siguiente: Artículo $3^{\circ}$. "La enumeración de los derechos establecidos en este capítulo no excluye los demás que la Constitución garantiza, ni otros de naturaleza análoga o que se fundan en la dignidad del hombre, o en los principios de soberanía del pueblo, del Estado democrático de derecho y de la forma republicana de gobierno". 
Para Carmen Hernández, la maternidad subrogada justamente sería nula por ir contra la moral y el orden público, ya que el objeto es la persona misma y se atenta contra su dignidad. En segundo lugar, estima que se pretende negociar con algo que es extra commercium, no pudiendo ser entonces objeto del contrato. En tercer lugar, la causa del contrato sería ilícita, y por tanto no produciría efectos jurídicos; y, en cuarto lugar, las normas de Familia son de ius cogens, no pudiendo las partes establecer cláusulas o convenios al amparo del principio de autonomía de la voluntad. ${ }^{19}$ Señala Vila-Coro, por su lado, que el referido contrato tiene causa y objeto inmorales y contrario a las buenas costumbres. ${ }^{20}$

Un tema discutido, vinculado con el mismo artículo 7 de la Ley General de Salud, es el tema de la "cesión de óvulos", "donación de óvulos" u "ovodonación". Si bien ella se viene dando sin mayores objeciones en la práctica en nuestro medio, lo cierto es que dicha norma es clara al decir que se permite el uso de técnicas de reproducción asistida, "siempre que la condición de madre genética y de madre gestante recaiga sobre la misma persona", es decir, que quien aporte el óvulo y quien haga el embarazo sean la misma persona, con lo que -contrariu sensu-, si dicha condición no se da, entonces no podría recurrirse a las referidas técnicas. ${ }^{21}$

De una revisión integral y sistemática del ordenamiento jurídico peruano, considerando que este reconoce expresamente el derecho a la identidad de cada persona -art. 2 inc. 1) de la Constitución-, así como el derecho a la verdad y a saber, además del principio del interés superior del niño, consideramos que es perfectamente amparable el reconocimiento en el Perú del derecho al conocimiento del origen biológico de las personas nacidas mediante las técnicas de reproducción asistida.

En nuestra doctrina, opina Marcial Rubio que los hijos nacidos mediante las técnicas artificiales de reproducción humana tienen el derecho a conocer la identidad de sus progenitores, al amparo de la Constitución, facultad

19 Hernández Ibáñez, Carmen (1992) Consecuencias jurídicas en torno a la fecundación asistida. En: Varios autores. Biotecnología y futuro del hombre: la respuesta bioética. Madrid: Eudema, S.A. (Ediciones de la Universidad Complutense S.A.), p. 52.

20 Vila-Coro, María Dolores (1995) Introducción a la Biojurídica. Madrid: UniversidadComplutense. p. 219.

${ }_{21}$ Vale decir que en una sentencia de la Sala Suprema en lo Civil de fecha 11.08.2012, el colegiado afirma que la ovodonación puede aplicarse válidamente en nuestro país (CAS No. 4323-2010), mientras que, para Torres Flor, el art. 7 de la Ley General de Salud, no solo impediría la donación de óvulos, sino incluso contendría una prohibición tácita respecto a la aplicación de cualquier técnica heteróloga, es decir, incluyendo también la de espermatozoides (Torres Flor, Analucía, 2014. Derecho a la identidad y reproducción humana asistida heteróloga. Arequipa, Universidad Católica San Pablo, p. 244-245). Para un análisis más amplio de la materia y la opinión del suscrito, nos remitimos al artículo "Consideraciones jurídicas en torno a la ovodonación", publicado en el número anterior de esta misma revista. 
que está por encima de las decisiones de quienes lo engendraron, pues la identidad es un derecho estrictamente personal que no se podría negar invocando la intimidad ${ }^{22}$. También se pronuncia a favor del derecho a la identidad en la materia Vanessa Cabrera, quien tiene una tesis expresamente sobre el tema. ${ }^{23}$

Desde un punto de vista conceptual, como señala Plácido, se debe "afianzar el derecho de toda persona a conocer y preservar su identidad filiatoria, con prescindencia de las circunstancias fácticas en las que se desarrolló el acto procreativo, por la consideración primordial del interés superior del niño", dándose preferencia a la realidad biológica independientemente de que la impugnación sea matrimonial o extramatrimonial. ${ }^{24}$

Juan Espinoza, por su parte, sostiene que tanto el hijo adoptivo, como el que es producto de las técnicas de reproducción asistida, cuando cumplan la mayoría de edad, tienen el derecho de conocer quién fue su progenitor biológico para defender sus intereses, incluyendo su salud, como podría ser el caso en que necesite un trasplante de riñón, para lo que se requiere de un pariente biológico que altruistamente lo ceda. ${ }^{25}$ Sin perjuicio de ello, considera que el factor determinante de la paternidad es el animus, la común intención del hombre y de la mujer que declaran tal deseo, planteando entonces la prevalencia de una definición dinámica de la paternidad antes que estática como la que plantea la relación padre $=$ progenitor. ${ }^{26}$

Por otro lado, aunque refiriéndose al derecho a la identidad en general (sin precisar el tema específico de los nacidos mediante técnicas de reproducción asistida), destaca Huamancayo ${ }^{27}$ que este incluye el derecho a conocer su padre biológico.

22 Entrevista citada por Rodríguez-Cadilla Ponce, Rosario (1997) Derecho Genético: Técnicas de Reproducción Humana Asistida, Su trascendencia jurídica en el Perú. Lima: Editorial San Marcos, p. 163-164.

23 Como señala Cabrera Palomino (2013) "La afectación del derecho de identidad de los nacidos bajo la ejecución del procedimiento de ovodonación por la inseguridad jurídica para la determinación de la filiación materna". En: Alétheia, Revista de la Escuela de Postgrado de la Universidad Femenina del Sagrado Corazón, año 1, No. 1, enero-diciembre 2013. Lima: UNIFE, p. 105.t., p. 105), quien ha escrito una tesis vinculada con el tema, frente al tema de la reserva y confidencialidad en cuanto al donante de material genético, ella no puede ser extendida hacia el resultado de dicha reproducción asistida, pues, sobre ella debe primar en el nacido, el derecho a saber y conocer su identidad.

24 Plácido, A. (2010) La Evidencia Biológica y la presunción de paternidad matrimonial. En: Iuris Consulto, No. 2. Lima: Universidad San Ignacio de Loyola, enero 2010. pp. 212 y 216.

25 Espinoza Espinoza, Juan (2012) Derecho de las Personas. Concebido y Personas Naturales. Tomo I. 6a. Edición Lima: Grijley, p. 107.

26 Ibid., p. 108.

27 Huamancayo Pierrend, Juan Carlos (2009) Op. cit., p. 139. Como conclusión del artículo en el que aborda el tema, señala el mismo autor que: "No es posible establecer en forma general si ha de preferirse en todos los casos el aspecto del derecho a la identidad, que estaría formado por los vínculos que mantiene todo sujeto con las personas que considera parte de su entorno o el derecho a la verdad biológica de su filiación; sino que ello se determinará en atención a las características particulares de cada sujeto" (Ibid., p. 143). 
Luego de tratar el tema de la negación de la paternidad en la inseminación artificial, Tafur y Ajalcriña plantean que "podría consagrarse un sistema "abierto de impugnación" que no se limite a supuestos taxativos previstos y que no admiten extensión analógica. ${ }^{28}$

Vale recordar que, antiguamente, nuestros códigos civiles prohibían la investigación judicial en el caso de los hijos extramatrimoniales en general, aduciendo el escándalo que la investigación generaría y la consiguiente perturbación de la paz familiar, "razón" que "ha sido desde hace mucho tiempo superada, privilegiándose a la justicia de otorgarle al menor el vínculo jurídico-familiar que le corresponde y al cual tiene derecho", como señala Martínez Coco. ${ }^{29}$

Rodríguez Cadilla, por su parte, si bien plantea que la cesión de material genético debe tener el carácter de anónima, quedando los datos del cedente en el más estricto secreto, agrega inmediatamente que la identidad del cedente, sin embargo, podrá ser revelada por orden judicial en casos de comprobado peligro para la vida del hijo o delembrión, ocuando así proceda conforme la ley penal, y siempre que dicha revelación sea indispensable para evitar el peligro o esclarecer el destino que se investigue. La revelación debe quedar restringida al ámbito médico/terapéutico y/o judicial, no admitiéndose en ningún caso la publicidad del donante. Anota, finalmente, la misma autora, que la revelación de la identidad no implicará filiación de ninguna manera. ${ }^{30}$

Varsi, por su parte, destaca el carácter innato del derecho a conocer el origen biológico, señalando que toda persona tiene derecho a conocer su filiación, como facultad propia y natural, no sólo para generar consecuencias legales, sino también para permitir la concreción y goce de su derecho a la identidad; sin perjuicio de ello, resalta que no siempre existe correlación exacta entre la paternidad jurídica y la paternidad biológica aun cuando el derecho trate de apoyar la primera en la segunda; la identidad filiatoria puede no coincidir con la identidad genética. ${ }^{31}$

28 Tafur Gopioc, Esperanza y Rita E. Ajalcriña Cabezudo. Negación de la paternidad en la inseminación artificial. En: APECC Revista de Derecho, p. 129.

29 Martínez Coco, Elvira (1998) La filiación biológica y el artículo 402 del Código Civil. En: Seijas de Jesús, Teresa (compiladora). Estudios sobre los aspectos jurídicos de la biotecnología reproductiva humana en el Perú. Lima: Editorial San Marcos, p. 81.

30 Rodríguez-Cadilla Ponce, Rosario (1997) Op. cit., p. 227-228.

31 Varsi, Enrique (1999) Filiación, derecho y genética. Lima: Fondo de Cultura Económica-Universidad de Lima, p. 251 y siguientes. 
Jairo Cieza reconoce también el derecho del nacido mediante técnicas de reproducción asistida de saber quién es su madre biológica, pero señalando que ello de ningún modo implicará reconocimiento de filiación. ${ }^{32}$

Pronunciándose sobre la posibilidad de pedir la paternidad de un hijo reconocido por otra persona, Mosquera Vásquez estima que ante todo está el derecho del niño a conocer su propio origen biológico, teniendo en cuenta los artículos 7 y 8 de la Convención de los Derechos del Niño y la importancia de que la verdad jurídica se acerque a la verdad biológica. ${ }^{33}$

Torres Maldonado, por su parte, señala que no puede privarse a una persona del conocimiento de sus raíces biológicas, pero excluyendo cualquier acción de filiación por ello, pudiéndose excepcionalmente revelar la identidad del dador por razones debidamente fundamentadas y evaluadas por una autoridad judicial. ${ }^{34}$

A su vez, en un libro completo publicado en nuestro medio, dedicado al estudio del derecho a la identidad y la reproducción asistida heteróloga, Torres Flor sustenta que, en consideración del principio del interés superior del niño, debe valorarse "la superioridad de los derechos de estos últimos, frente a las pretensiones de sus padres sociales y el derecho a la intimidad genética del donante anónimo, los cuales deben ceder frente al derecho a la identidad genética de los hijos matrimoniales concebidos mediante las técnicas", agrega que siendo el derecho a la identidad genética parte de la identidad personal, el cual constituye expresión de la unidad propia del ser humano, agregando que:

“... el Estado debe garantizar el ejercicio del derecho a la identidad personal a través del reconocimiento del derecho a conocer el propio origen biológico, el cual no se satisface con la mera revelación de datos personales, sino que implica el legítimo derecho a tener contacto con quienes serían sus progenitores genéticos e

Cieza, Jairo (2011) Op. cit., p. 3.

En: La Ley, año 6, No. 65. Lima: edición del 1 al 30 de junio de 2013, p. 8.

34 Torres Maldonado, Marco Andrei (2013) ¿Mi papá es un donante? El eufemismo del interés superior y la identidad del menor derivada de las técnicas de reproducción humana asistida. En: Gaceta Civil y Registral, Tomo 152. Lima: octubre 2013, p. 156 y siguientes. “... el conocer el propio origen es un derecho fundamental de toda persona, relacionado (en cuanto que la determina) con su identidad de persona concreta y diferente de cualquier otra (...) El anonimato de los dadores no supone una absoluta imposibilidad de determinar su identidad, pues, de manera excepcional, en circunstancias extraordinarias que comporten un comprobado peligro para la vida del hijo, o cuando proceda con arreglo a las leyes procesales penales, podrá revelarse la identidad del dador y también permite a los hijos obtener información general de los dadores, excepción hecha de su identidad lo que garantiza el conocimiento de los factores o elementos genéticos y de otra índole de su progenitor" (Ibid., p. 167). 
incluso establecer vínculos jurídicos filiatorios a través de las acciones de estado correspondientes". 35

Es de mencionar aquí otro interesante libro, escrito por la profesora de la Universidad de Piura, Maricela Gonzáles de Castro, quien ofrece un estudio muy completo sobre la verdad biológica en la determinación de la filiación; si bien el trabajo se ocupa fundamentalmente del tema en relación a la legislación española y europea, contiene conceptos que son de gran utilidad para abordar la problemática en nuestro medio. Para la citada autora, el anonimato del donante resulta inconstitucional, generando situaciones de discriminación y de limitación de derechos, añadiendo:

"Además, el anonimato del dador transgrede el principio de indisponibilidad del estado civil de los hijos, a quienes se les instrumentaliza. Esto último supone una verdadera violación de su dignidad como persona, por lo cual, no sólo el anonimato del donante, sino las técnicas en general, pierden toda legitimidad. Ese deseo de "tener un hijo" por parte de adultos solteros, estériles, homo o heterosexuales, no puede prevalecer sobre el bienestar del niño". ${ }^{36}$

Para concluir con esta revisión del tratamiento del tema en la doctrina y en la legislación nacional, vale decir que el Grupo de Trabajo designado por el Poder Ejecutivo para reglamentar las técnicas de reproducción asistida, trató también el tema, habiendo invitado al suscrito para presentar las ideas que planteamos en el presente trabajo en sesión de fecha $1^{\circ}$. de octubre del año $2014 .{ }^{37}$ La referida comisión ha cumplido con presentar su informe final al Ministerio de Justicia, mas a la fecha -noviembre del 2015- éste no ha sido publicado para su discusión; aparentemente, al menos por el momento, no sería un tema en las prioridades políticas, distraídas más bien en cuestiones de coyuntura, habiendo un ambiente poco propicio para poner sobre el tapete un proyecto sobre temas tan delicados.

\section{CONSIDERACIONES ADICIONALES Y REFLEXIONES FINALES}

El derecho a conocer el origen biológico se vincula también con la aparición de diversos estudios científicos que han puesto en evidencia una

\footnotetext{
Torres Flor, Analucía (2014) Op. cit., p. 246.

Gonzáles Pérez de Castro, Maricela (2013) La verdad biológica en la determinación de la filiación. Madrid: Dykinson - Universidad de Piura, p. 257-258.

37 El Grupo de Trabajo fue designado por el Gobierno para elaborar un proyecto de ley sobre técnicas de reproducción humana asistida y otros temas vinculados con la Bioética, siendo conformado mediante Resolución Ministerial $\mathrm{N}^{\circ}$ 0271-2013-JUS, del 4 de diciembre de 2013 y modificado a través de Resolución Ministerial N 0195-2014-JUS, del 3 de septiembre de 2014.
} 
mayor predisposición de los nacidos por esta vía para desarrollar ciertas enfermedades (prematuridad en el nacimiento, bajo peso, problemas circulatorios a largo plazo, generación de determinados síndromes, etc). Ello es, aparte por cierto, de otras razones de salud más difundidas como la necesidad de conocer la mayor predisposición hereditaria a sufrir de determinadas enfermedades y riesgos hereditarios en general, además de la necesidad de evitar relaciones incestuosas.

Aparte de las razones expuestas, estimamos que el conocimiento del origen biológico es un derecho natural de toda persona; más todavía, siendo algo que por su contenido es tan fundamental para cada uno.

"Poder conocer su propia génesis, su procedencia, es aspiración connatural del ser humano que, incluyendo lo biológico, lo trasciende. Tender a encontrar raíces que den razón del presente a la luz del pasado que permita reencontrar una historia única e irrepetible en movimiento (...)" ${ }^{38}$

Negar este derecho, sería, además, discriminatorio, pues tendríamos un grupo de personas que sí pueden conocer sus orígenes (los nacidos por medios ordinarios), mientras otro grupo de personas no podrían gozar de ese mismo atributo (los nacidos por medios extraordinarios). ${ }^{39}$

Aparte, se estaría yendo contra el deber que tienen los padres de decir la verdad a sus hijos, y violando el respeto a la dignidad de éstos al ocultarle información de modo paternalista cuando ya no son menores de edad.

Conforme al principio de autotelia del que habla Miró Quesada Cantuarias ${ }^{40}$, siguiendo a Kant, cada hombre debe ser tratado como un fin en sí mismo y no como un medio. Tratar a alguien como un fin en este caso significa confiar en él, en su capacidad de discernimiento, de comprensión, en darle oportunamente toda la información que sea de su interés, más allá de cualquier sentimiento o interés personal.

38 "La filiación y el derecho a la identidad" (síntesis de trabajo de la Dra. María Silvia Apud Ahualli, publicado en La Gaceta. Tucumán, Argentina, edición del 02.10.2007). Disponible en internet : www.Lagaceta.com.ar/nota/238069/ tribunales. Consultada el 05 de marzo de 2013.

39 "La exigencia de un anonimato absoluto discrimina a los hijos nacidos a partir de las nuevas técnicas de los demás" (Moro Almaraz, María Jesús (1988) Aspectos civiles de la inseminación artificial y la fecundación "in vitro". Barcelona: Bosch, p. 109)

40 Miró Quesada Cantuarias, Francisco (1992) Hombre, Sociedad y Política. Lima: Ariel-Comunicaciones para la Cultura, p. 121. Explica el distinguido maestro sanmarquino: “Que toda persona sea un fin en sí, significa que la meta de su existencia es el desarrollo máximo de todas sus posibilidades. El único límite es el de la no arbitrariedad (...) ninguna otra tiene el derecho de tomarla como medio para realizar sus propios fines. El hecho de tomar a otro como instrumento, significa que se le impone cauces arbitrarios". (Ibidem, p. 82). 
Vale reiterar que nuestro planteamiento de reconocer el derecho de toda persona a conocer su origen biológico, es independiente del tema de la determinación de la filiación legal y de los derechos económicos que ella pudiera determinar, cuestiones que escapan al alcance de la presente propuesta y que corresponde tratar en el marco del Derecho de Familia. En todo caso, vale decir que-como sostiene Morales Godo-, el solo argumento de la existencia de una relación genética no es de por sí suficiente para reclamar la paternidad, teniendo en cuenta razones de orden ético y jurídico; se tendría que pasar por dejar de lado la presunción "pater is..." (ya hoy en día en revisión) a partir de la negación de la paternidad del marido en el caso de la mujer casada, a efectos que el padre biológico pueda reclamar la suya ${ }^{41}$, tema sobre el que en el Perú existe ya jurisprudencia, de la que hemos dado cuenta en el presente estudio.

La filiación no puede reducirse al mero dato genético, como factor para determinar la paternidad, teniendo en cuenta que el ser humano es un ser cultural y social. La identidad de una persona implica no solo una verdad biológica, sino también una verdad sociológica, cultural y social; debe tenerse también en cuenta el tema de la posesión de estado.

Volviendo al tema del reconocimiento del derecho a la identidad biológica, tampoco puede dejarse de tener en consideración que en caso de conflicto entre la paternidad establecida por la ley y la paternidad biológica, debe tenerse en cuenta el principio del interés superior del niño.

Siguiendo a Pérez de Pablos la clave de la respuesta está en el hijo; frente a las antiguas leyes que protegían ante todo la voluntad de los padres, por las herencias o la presión social, debe anteponerse el derecho del niño a conocer a su padre o a su madre, haya sido adoptado, concebido gracias al semen de un donante, etc. y sea cual sea el país de origen de sus padres. ${ }^{42}$

Incluso, sea lo que sea que dicho principio determine en cada caso en concreto $^{43}$, respecto, por ejemplo, al otorgamiento de la patria potestad, ello es independiente del derecho de toda persona a conocer sus orígenes ${ }^{44}$, que le es inherente.

${ }_{41} \quad$ Morales Godo, Juan (2006) Op. cit., p. 426.

42 Pérez de Pablos, Susana. Pérez de Pablos, Susana (2008). Quiero saber quién es mi padre. En: Diario El País, edición digital. http://elpais.com/diario/2008/03/17/sociedad/1205708402_850215.html. Consultada el 19.10.2013.

43 Como dice González Pérez de Castro (2013, p. 145), el juzgador debe tener en cuenta que el interés del hijo no siempre se reduce a la verdad biológica.

44 En tal virtud, coincidimos con el profesor Benjamín Aguilar cuando expresa que: "pienso que el derecho a la identidad no debe quedarse con la filiación exclusivamente genética: en algunos casos sí habrá que buscarla, pero en otros casos el estado de familia hay que respetarlo: El estado de familia alude a la posesión constante de estado de 
En adición de los argumentos expuesto, es de invocar el principio pro homine, como criterio hermenéutico, según el cual debemos acudir a la norma más amplia, o a la interpretación más extensiva, a la hora de proteger derechos fundamentales. Por otro lado, desde la Bioética, tenemos los principios de autonomía, de dignidad de la persona y el derecho al consentimiento informado.

Si bien existen diversas razones que sustentan la existencia del derecho de toda persona a conocer su origen biológico, conforme a lo expuesto aquí y en otros trabajos, es fundamental incorporar expresamente en el Código Civil una norma que consagre el derecho de toda persona a conocer su origen biológico, independientemente de la técnica a través de la cual hubiere sido concebida, al amparo del derecho a la identidad consagrado en el artículo 2 de la Constitución.

Asimismo, debe establecerse que toda persona podrá acceder, si así lo desea, a la información que le competa, vinculada con sus orígenes, a partir de los 18 años de edad; ello podrá ser, por supuesto, antes por libre voluntad de sus padres, o si es que hubieren razones de salud que así lo justifiquen y que se acrediten ante un juez.

La ocasión es propicia, adicionalmente, para reiterar la urgencia de incorporar en los currículos de estudio de las Facultades de Derecho, por lo menos un curso de Bioética y Derecho, teniendo en cuenta éste y otros numerosos temas que demandan un estudio reflexivo y una adecuada capacitación, considerando las exigencias de los tiempos actuales, las nuevas demandas sociales y el desarrollo de la tecnología.

padre e hijo, el padre que se comporta como tal, aunque biológicamente no lo sea, vale mucho más que mil padres biológicos". Entrevista a Benjamín Aguilar Llanos (2012). En : Boletín Construyendo Justicia, Lima, Prosode, año XV, No. 73. Junio, p. 2. 


\section{REFERENCIAS}

Arias Stella Castillo, Fernando (2012) Derechos Humanos y las sentencias del Tribunal Constitucional que consagran el derecho a investigar la propia filiación. Lima: Instituto de Patología y Biología Molecular "Arias Stella".

Boletín Construyendo Justicia (2013) Lima: Prosode, año XV, No. 73. Junio. Cabrera Palomino, Vanessa (2013) La afectación del derecho de identidad de los nacidos bajo la ejecución del procedimiento de ovodonación por la inseguridad jurídica para la determinación de la filiación materna. En: Alétheia, Revista de la Escuela de Postgrado de la Universidad Femenina del Sagrado Corazón, año 1, No. 1, enero-diciembre 2013. Lima: UNIFE.

Cieza, Jairo (2011) La técnica de reproducción humana asistida y la Corte Suprema: ¿Quién entonces es la madre?.En: Revista Jurídica del Perú. Disponible en internet: http://legisprudencia.pe/blogs/2011/04/26/la-técnicade-reproducción-humana-asistida-y-la.corte-suprema-\%C2\%BFquienentonces-es-la-madre/.

Espinoza Espinoza, Juan (2012) Derecho de las Personas. Concebido y Personas Naturales. Tomo I. 6a . Edición Lima: Grijley.

Faiella, Rocío Liliana (2009) El ADN pone en jaque la inmutabilidad de la cosa juzgada. En: Revista Jurídica Aequitas. Facultad de Ciencias Jurídicas de la Universidad del Salvador. 3ª . Etapa. Año III. Número III.

Fernández Sessarego, Carlos (1992) Derecho a la identidad personal. Buenos Aires: Astrea.

Gonzáles Pérez de Castro, Maricela (2013) La verdad biológica en la determinación de la filiación. Madrid: Dykinson - Universidad de Piura.

Hernández Ibáñez, Carmen (1992) Consecuencias jurídicas en torno a la fecundación asistid". En: Varios autores. Biotecnología y futuro del hombre: la respuesta bioética. Madrid: Eudema, S.A. (Ediciones de la Universidad Complutense S.A.).

Huamancayo Pierrend, Juan Carlos (2009) El Derecho a la Identidad vs. el Derecho a la Verdad Biológica. ¿Se está aplicando correctamente el control difuso en el caso de los artículos 364 y 400 del Código Civil. En: Persona, Derecho y Libertad. Nuevas Perspectivas. Escritos en Homenaje al Profesor 
Carlos Fernández Sessarego. Calderón Puertas, Carlos, María Elisa Zapata J. y Carlos Agurto G. (Coordinadores) Lima: Editora Jurídica Motivensa.

La Gaceta. Tucumán, Argentina (2007) La filiación y el derecho a la identidad. Síntesis de trabajo de la Dra. María Silvia Apud Ahualli, edición del 2 de octubre de 2007. Disponible en internet: www.Lagaceta.com.ar/ nota/238069/tribunales. Consultada el 05.03.2013

Martínez Coco, Elvira (1998). La filiación biológica y el artículo 402 del Código Civil. En: Estudios sobre los aspectos jurídicos de la biotecnología reproductiva humana en el Perú. Seijas de Jesús, Teresa (compiladora). Lima: Editorial San Marcos.

Messineo, Francesco (1986) Doctrina General del Contrato. Tomo I. Buenos Aires: Ediciones Jurídicas Europa-América.

Miró Quesada Cantuarias, Francisco (1992) Hombre, Sociedad y Política. Lima: Ariel-Comunicaciones para la Cultura.

Morales Godo, Juan (2006) El estatus del concebido y la problemática de la fecundación asistida. En: Derecho. No. 58, Revista de la Facultad de Derecho de la Pontificia Universidad Católica del Perú. Lima: PUCP.

Morales Godo, Juan (2006) ¿Somos libres, seámoslo siempre? (A propósito de la autonomía de la voluntad y el orden público). En: Varios Autores. Libro Homenaje a Fernando Vidal Ramírez. Lima: Idemsa.

Morán de Vicenzi, Claudia (2008) La Filiación y la Fecundación Artificial. En: Varios autores. Temas de Bioética y Derecho. Lima: Cátedra Unesco de Bioética y Biojurídica-Facultad de Derecho de la Universidad Femenina del Sagrado Corazón.

Moro Alvaraz, María Jesús (1988) Aspectos civiles de la inseminación artificial y la fecundación "in vitro". Barcelona: Bosch.

Mosquera Vásquez, Clara (2010) Las técnicas de procreación asistida en los tribunales peruanos. En: Revista Diálogo con la Jurisprudencia No. 147. Lima: Gaceta Jurídica.

Olguín Britto, Ana María (2007) Los derechos de filiación en las técnicas de fecundación artificial. En: La Familia: Naturaleza y Régimen Jurídico en el 
Siglo XX. Jornadas Internacionales de Derecho de Familia. Chiclayo: Universidad Católica Santo Toribio de Mogrovejo.

Pérez de Pablos, Susana (2008).Quiero saber quién es mi padre. En: Diario El País, Disponible en internet: http://elpais.com/diario/2008/03/17/ sociedad/1205708402_850215.html. Consultada el 19.10.2013.

Plácido Vilcachagua, Alex (2010). La Evidencia Biológica y la presunción de paternidad matrimonial. En: Iuris Consulto, No. 2. Lima: Universidad San Ignacio de Loyola, enero 2010.

Rodriguez-Cadilla Ponce, Rosario (1997). Derecho Genético: Técnicas de Reproducción Humana Asistida. Su trascendencia jurídica en el Perú. Lima: Editorial San Marcos.

Siverino, Paola (2013). Cuestionamiento de la filiación matrimonial por la esposa. En: Revista Diálogo con la Jurisprudencia No. 179. Lima: Gaceta Jurídica, agosto.

Tafur Gopioc, Esperanza y Rita E. Ajalcriña Cabezudo. “Negación de la paternidad en la inseminación artificial". En: APECC Revista de Derecho.

Torres Flor, Analucía, (2014) Derecho a la identidad y reproducción humana asistida heteróloga. Arequipa, Universidad Católica San Pablo.

Torres Maldonado, Marco Andrei (2013) ¿Mi papá es un donante? El eufemismo del interés superior y la identidad del menor derivada de las técnicas de reproducción humana asistida. En: Gaceta Civil y Registral, Tomo 152. Lima: octubre.

Varsi Rospigliosi, Enrique (1999) Filiación, derecho y genética. Lima: Fondo de Cultura Económica-Universidad de Lima.

Vila-Coro, María Dolores (1995) Introducción a la Biojurídica. Madrid: Universidad Complutense.

Fecha de recepción : 20 de agosto de 2015

Fecha de aceptación : 24 de setiembre de 2015 
